\title{
Study of Laser Angioplasty using Angioscope- Fluorescence Analyzer System (AFAS)
}

\author{
Hiromori Shiraishi, Takayuki Asahara, Tomitsugu \\ Katou, Mikio Usui, Yasuhisa Oike, Hiroyuki Rakue, \\ Yuiti Naitou, Ikuhiro Yamazawa Chiharu Ibukiyama \\ The 2nd Dept. of Internal Medicine Tokyo Medical \\ College
}

Angioscope-Fluorescence Analyzer System (AFAS) Which can be employed simultaneously as an angioscope together with real-time fluorescence spectroscopy has been studied in our laboratory. This study reports in vitro and in vivo Laser Angioplasty (LA) under AFAS diagnosis using a photosensitizer. Nd-YAG LA using a contact ceramic tip and in vitro AFAS diagnosis were performed on the aortas of sacrificed 7 athroscleotic rabbits (AR) which had been given Dehematoporphyrin ethyl (DHE), a photosensitizer, $24 \mathrm{~h}$ befor. The 72 sites of LA were histologically examined. Next, in vivo LA and AFAS evaluation were performed by alternately inserting the necessary catheter through the femoral artery in same treated 5 AR. Remarkable correlation $(R=0.759)$ was observed between the residual intimal thickness after in vitro LA and $630 \mathrm{~nm}$ fluorscence intensity. Fluorescence spectrums were devided to three type. "Typel" has $630 \mathrm{~nm}$ and $690 \mathrm{~nm}$ peak pattern which is specific for DHE, and "Type 3" has 620nm and $670 \mathrm{~nm}$ peak pattern". Type 2 is medium type. "Type $3 "$ site was in accordance with that of calcification of atherosclerosis. In the in vivo study, as the LA procedure progressed, DHE specific fluorescence decreased and disappeared when the media became completely exposed. AFAS can be a feedback diagnosis system for LA to prevent perforation of blood vessels.

锗言

冠状動脈に招ける Laser angioplastyを安全に 施行方る為の检討が各施設で行われている。

我々は，光感受性物質を用いた診断乙治療につい て検傠してきたが, 本研究では, 血管内視鏡観察 と虽光スペクトル解析を同時江施行出来る, 血管 内視鏡蛍光スペクトル解析装置 Ang ioscope-Flu orescence Analyzer System (以下AFS と略す) を使用して, Spectroscopic Monitoringしながら Laser angioplastyを安全に行う力法を検討した。

\section{【1方法及び絬舁}

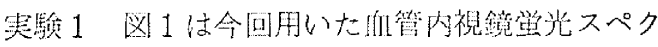
トル解析装䈯の模式図である。上段に示すのが向l 管内視鏡機能，下段に示すのが䖺光スペクトル測 定機能である。雨機能加ら得られた内視鏡像之蛍 光スペクトル波形がReal Time 江同一画面に描 画される。

動㟲硬化モデルとして, Fogarty Balloon Catheter にて内膜を損傷し, $2 \%$ レステロール

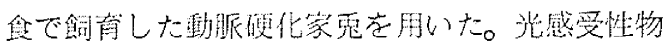
翼 Dehematop rphyr in ethyl (DHE) $5 \mathrm{mg} / \mathrm{Kg}$ 24

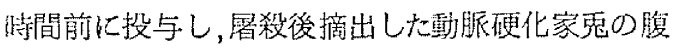




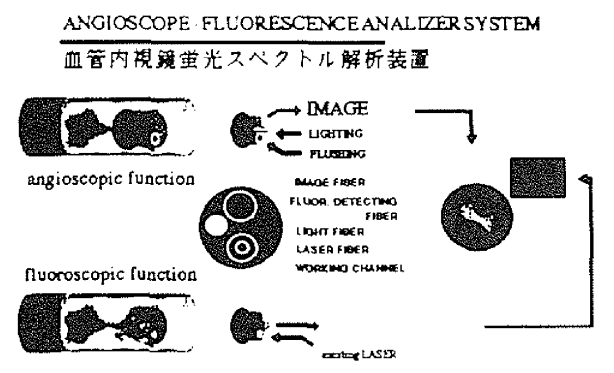

図 1 血管内視鏡営光スペクトル解析装㽡の模 式図

部大動脈を室温生食中に固定してContact Laser Tipを使用し,Nd-YAG Laser 照射を(1〜30J)施 行した。また同部位をエキシマダイレーザー( 405 $\mathrm{nm}$ )にて励起してその部位の虽光スペクトル波形 を記録した。照射部位および周辺の非照射部の蛍 光スペクトルを測定した後， $\mathrm{H}-\mathrm{E}$ 染色で組 織学的に検討した。動脈硬化家兔の照射部 位残存内膜と监光スペクトルの関係省調べたと ころ，波形は630nm および $670 \mathrm{~nm}$ にピーク を有す る Type 3 の二種類に大别され，その中間型学 Type 2 と分類した。

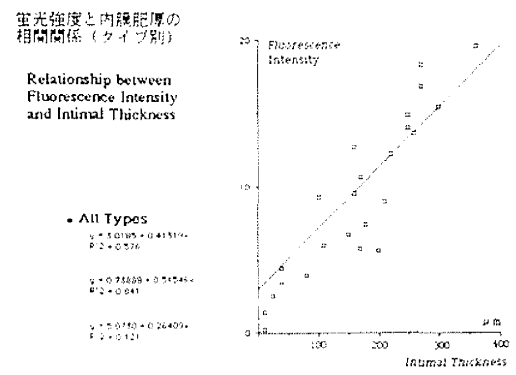

図 2 営光強度之内膜肥曆の相関関係

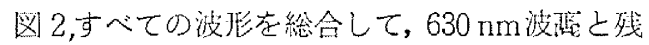

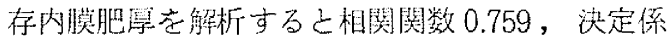
数 0.576 の正相関関係老認めた。てれをType $1+$
Type 2 に限ると，两者は相関孫数 0.917 , 決定係 数 0.841 亡強い相関関係を得た。一万Type 3 で は，䦌者は相関係数 0.348 , 決定係数 0.121 亡なり 相関関係老失なった。

Type 1 の組繀学的所見は, 動脤硬化内膜組胞 老主体として残存しており, Type 2 は敖面加ら距 離を有する動脈硬化石灰化が存在し, Type 3 は,

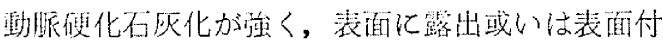
近に存在する倾问認めた。

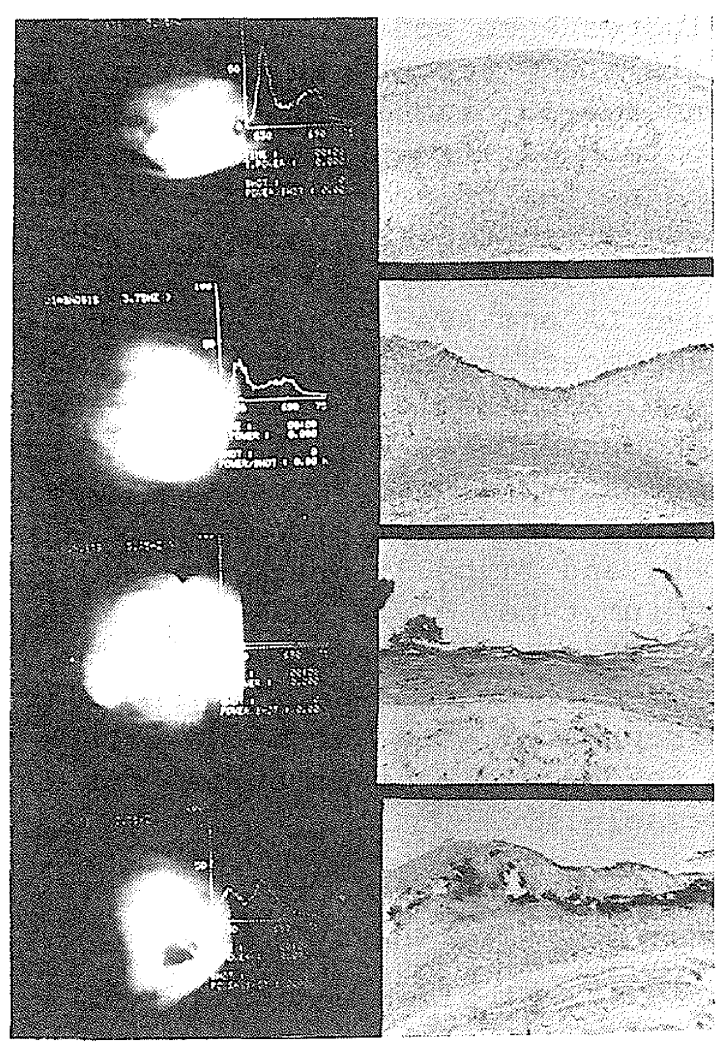

図3 レーザー治療中の血管内視鏡所見と蛍光 スペクトル，HE染色所見

図 3 レーザー照射による肥厚内膜蒸散で, 残存 内膜が減少するのに伴い䖝光スペクトル波高の減 弱が認められた。中膜が路出すると, 光感受性物 質DHEの蛍光は消失するととが判明した。一番 下の段はType 3 の䖝光スペクトル波形を示して

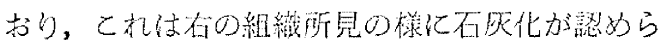


れた。

実験 2 次にIN V I VO実験を施行した。D HE $5 \mathrm{mg} / \mathrm{kg}$ 党 24 時閏前に投与した動脈硬化家

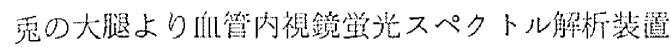
を挿入し，動脈硬化部位を維察测定した後に照射 部位を決定し Contact Laser Tip 使用し, Nd - YAG Laser照射( $1 \sim 5 \mathrm{~W}, 1 \mathrm{sec})$ を施 行した。照射部位および䧓辺の非照射部の営光ス ペクトルを测定した後, $\mathrm{H}-$ E染色で組織学的に 検討した。

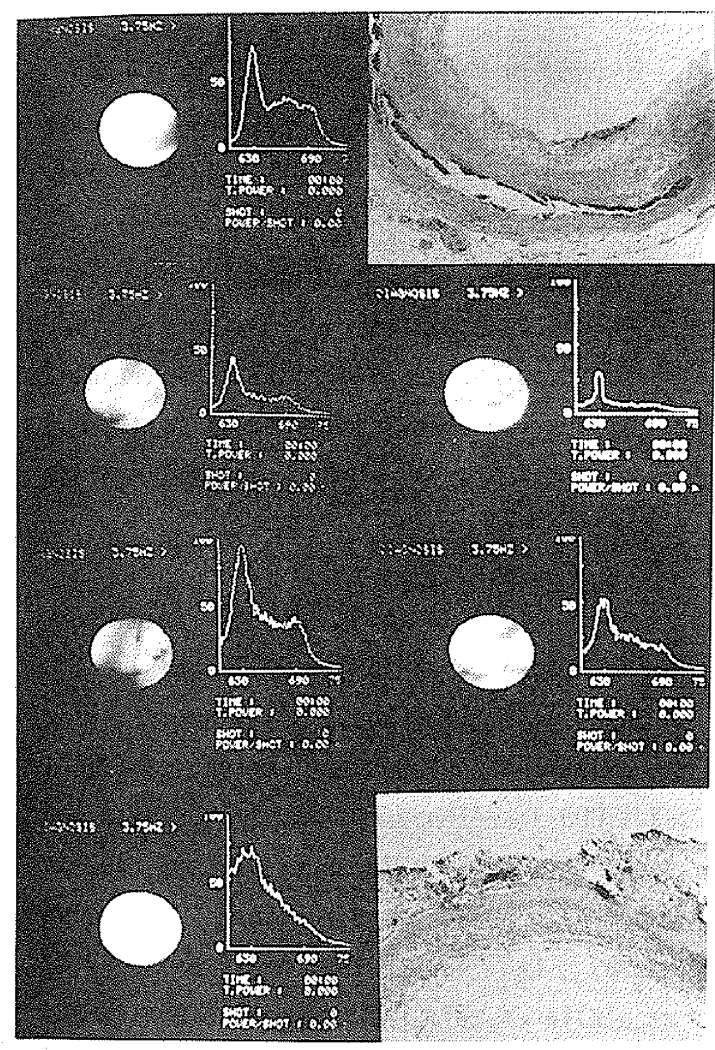

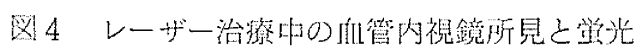
スペクトル，HE染色所見

图 4 Laser Angioplasty を施行しながら記録 した的管内視鏡所見と䖝光スペクトル波形を示し ている最上段はType 2 波形で同部位に哚在性の

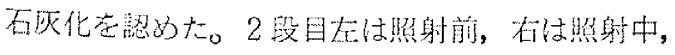
3段目大は照射 1 回後, さらに照射在進めてゆき
最下段左の波形で照射を中止した。同部位の組織 所見では残存内膜はほとんど消失し, 中膜の露出 を認めた。照射が進むにつれてBase Lineが高く なってゆくのは中膜の自家蛍光を感受しているた めと思われた。

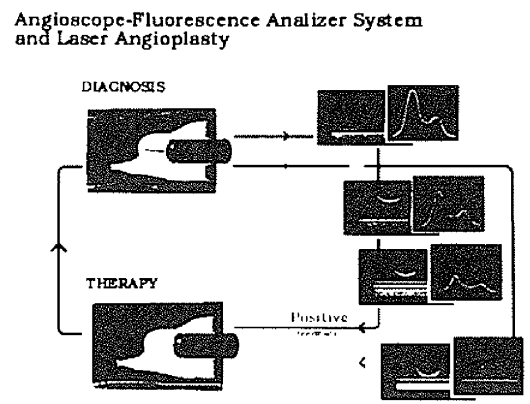

脑 5 A F A S を用いた Laser Angioplasty の模式図

困 5 Iffl管内内視鏡営光スペクトル解析装琶之光感受 性物質を用いて Spectroscopic Monitoring を施 行しながら安全にLaser Angioplastyを行ってい る模式図である。

洘案

動脈硬化部位をIn[管内視鏡で肉眼的缴察定行う と同時に䖝光スペクトル解析を行って, 残存内膜 老確認しながら治療を進めて行き，中膜が露出す るところで治療を停止すれば血管穿孔の心配然く， 理想的なLaser Angioplasty が可能と考え, 本研 究を湤行した。結果は当初の狙いどうり良好な結 果を得た。1.光感受性物質を用いた，より低出力 での動脈硬化部位内膜の烝散。2) 2. 光感受性物質在 用いた，動眽硬化部位内膜の診宩。3.動脈浭化部 位内膜の蒸散と伴に光感受性物質の虽光減弱。そ れら特性をより一首生かすことによってより安全な Laser Ang ioplas ty が可能となると考えられた。

縤語

Ifill管內視鏡䖢光スペクトル解析装琶を用いた 
Spect rosocopic Moni toring により動㟲硬化部 位内膜の質的, 量的診断が可能となり，レーザー 血管形成術の進行状況を把握出来，血管穿孔を未 然に防ぐフィードバック機構確立の可能性が示さ れた。

\section{参考文献}

1）浅原孝之，中島 均，他。光感受性物質を用 いたLaser Angioplasty の基整的研究：日本レ ーザー医学会誌 $1988 ； 9(3) ， 61-64$

2）中島 均ほか。心淽血管レーザー形成術の基 嘫 - 冠動脈硬化病変に対する作用を中心に一; 南江堂「心臟血管内視鏡・レーザー形成術」掲載 予定。 